University of San Diego

Digital USD

Spring 5-25-2019

\title{
Promoting Diabetes Self-Management Education and Support in Primary Care Clinic: An Evidence-Based Project
}

Maricel Veluz Delacruz

University of San Diego, maricelvdelacruz@sandiego.edu

Follow this and additional works at: https://digital.sandiego.edu/dnp

Part of the Nursing Commons

\section{Digital USD Citation}

Delacruz, Maricel Veluz, "Promoting Diabetes Self-Management Education and Support in Primary Care Clinic: An Evidence-Based Project" (2019). Doctor of Nursing Practice Final Manuscripts. 94.

https://digital.sandiego.edu/dnp/94

This Doctor of Nursing Practice Final Manuscript is brought to you for free and open access by the Theses and Dissertations at Digital USD. It has been accepted for inclusion in Doctor of Nursing Practice Final Manuscripts by an authorized administrator of Digital USD. For more information, please contact digital@sandiego.edu. 
Running head: PROMOTING DSMES IN PRIMARY CARE CLINIC: AN EBP PROJECT

PROMOTING DIABETES SELF-MANAGEMENT EDUCATION AND SUPPORT IN PRIMARY CARE CLINIC: AN EVIDENCE-BASED PROJECT

\author{
Author: \\ Maricel Veluz Delacruz, MSN, FNP-C, APRN \\ DNP Candidate \\ University of San Diego
}




\section{ACKNOWLEDGEMENTS}

I hereby acknowledge and give thanks to the owner of the private practice clinic and my clinical mentor, Dr. Arwinnah Bautista, MD, for agreeing to have my project be conducted at her private primary clinic. I also recognize Winefrida Robichoud, the clinic's medical assistant and office manager, as well as Nenita Mehlmauer, the clinic biller, facilitator of insurance preauthorization request, and the clinics' expert in information technology. The support that they provided made it possible for me to complete this evidence-based practice (EBP) project.

I am grateful to have a supportive faculty chair, Dr. Razel Milo, faculty advisors Dr. Joseph Burkard and Dr. Tanna Thomason, for their guidance that enables me to complete this EBP project successfully. Special thanks to Dr. Karen McCauley for accepting me to the DNP program and for giving me the chance to be a part of this prestigious university. My journey to the University of San Diego has given me the opportunity to explore and recognize my abilities to reach my potential capabilities in improving my nursing profession. I also mention Dr. Carlota Quiban, Dr. Maria Luisa Ramira, and Donald Laurino, for helping me reach my goal of achieving the Doctor of Nursing Practice (DNP) program.

Finally, I thank my husband, Greg Delacruz, for providing me unconditional support, motivation, confidence, and for believing in me, believing that I will be able to make it at this level of education without hesitation. My thanks to my mother, family, and friends who encouraged me to be where I am right now in my educational journey. The completion of this EBP project is the reflection of hard work, perseverance, and support that I received from the people who inspired me. 


\begin{abstract}
Objective: Self-care disease management is a crucial component in achieving healthy glycemic targets among type 2 diabetes mellitus (T2DM) patients to improve health outcome resulting in reduced healthcare cost. The purpose of this evidence-based practice (EBP) project is: 1) to improve hemoglobin glycated (A1C) levels to $\leq 7 \%$ through utilization of diabetes selfmanagement education and support (DSMES) and diabetes self-management questionnaire (DSMQ); 2) to increase patients self-care practices related to T2DM and grow clinic revenue.
\end{abstract} Research Design and Methods: The EBP project took place in a private primary clinic in National City, California. A total of eight T2DM respondents with an A1C level of $\geq 7 \%$ were included to partake in the EBP project. A 30-minute Diabetes Self-Management Education and Support (DSMES) utilizing the designated seven self-care behaviors of the American Association of Diabetes Educators (AADE) and a telephone follow-up; and administration of DSMQ were provided to respondents as interventions. Both A1C levels and DSMQ were obtained at baseline and during follow-up after 3 to 8 months.

Results: Tailored individualized DSMES utilizing various evidence-based interventions resulted in reduced average A1C levels from 8.8\% to 7.5\% and increased DSMQ scores from 11.1 to 19.8 after project interventions.

Conclusions: A combination of various self-care management strategies promotes healthy glycemic control in this patient population. DSMES according to individuals' need and preference increases patient's engagement to self-care activities related to T2DM. A1C levels within the American Diabetes Association (ADA) recommendation can ultimately increase practice revenue and reduce healthcare cost. 


\section{INTRODUCTION}

\section{Problem Description}

Type 2 diabetes mellitus (T2DM) is a chronic metabolic disease that causes substantial mortality and infirmity among American people (Bullard et al., 2015). The complexity of T2DM care often makes it difficult for patients to comply with the treatment regimen agreed upon with their healthcare professionals, including lifestyle changes, diet, and/or pharmacotherapy (GarciaPérez, Alvarez, Dilla, Gil-Guillen, Orozco-Beltran, 2013). The American Association of Diabetes Educators (AADE; 2017) revealed that, according to recent research, only $45 \%$ of patients monitor blood glucose, an average of just $25.5 \%$ follow physical activity and weight loss instructions, and merely $85 \%$ of patients take their medications as prescribed. Non-compliant patients require particular focus as they may continually need reinforcement of behavioral changes to sustain glycemic control (Shrivastava, Shrivastava, \& Ramasamy, 2013).

In the private practice within which this EBP was conducted, $16 \%$ of patients were diagnosed with T2DM during data collection from May 2018 to February 2019. A total of 21.4\% of diagnosed T2DM patients have $\geq 7 \%$ A1C level. Common T2DM complications seen in the clinic include nephropathy, peripheral neuropathy, and cataract requiring surgery. The patients' lack of perceived importance of self-care management and the absence of the Diabetes SelfManagement Education and Support (DSMES) guidelines in this primary care clinic has brought this EBP project into realization.

The majority of the respondents belonged to the older adult population who were medically underserved and belonged to a minority ethnic group. Older adults diagnosed with T2DM contribute to the fast-growing worldwide diabetes epidemic (Kalyani, Golden, \& Cefalu, 2017). Furthermore, one-third of adults over 65 years in the US were diagnosed with T2DM- 
contributing to the unprecedented growing healthcare burden. This age group often suffers from multiple chronic conditions and polypharmacy, necessitating further self-care management education and support to reach a glycemic target (Sherifali, Bai, Kenny, Warren, \& Ali, 2015).

The role of healthcare providers is essential in promoting self-care management skills at the primary care level, specifically to the population that this primary clinic serves in order to attain the recommended healthy glycemic control. Making a personalized, realistic, and specific self-care activities program are essential to sustain glycemic control. Adherence to treatment is imperative in attaining success, to significantly improve glycemic outcomes among T2DM patients, and to improve health outcomes and quality of life (AADE, 2017; Powers et al., 2017).

The recent innovative campaign conducted by the CDC (2017) on enhancing the DSMES programs intends to ultimately make it more available in the community. The hope is to promote change in self-care behaviors to decrease the number of people diagnosed with T2DM and increase the number of T2DM patients within the recommended glycemic limit, consequently preventing further complications and ultimately reducing healthcare cost.

\section{Background and Evidence of the Problem}

Despite various preventive care advances, the rising incidence of T2DM continues to remain a growing healthcare burden resulting in escalating healthcare costs. In 2015, the CDC (2017) reported that T2DM is the 7th leading cause of death in the US - where medically underserved and minorities are the most vulnerable populations. Approximately $9 \%$ of the US population were diagnosed with T2DM — this is nearly 30.3 million Americans, while 7.2 million were undiagnosed. About 84.1 million were prediabetic and were not aware that they have it, which later, if not addressed, will progress to T2DM diagnosis (CDC, 2019). An 
anticipated 54\% increase of T2DM will cost up to 622 billion dollars for direct and indirect medical services by 2030 (Rowley et al., 2017).

In 2015 , an estimated $9.8 \%$ and $9.9 \%$ of adults were diagnosed with T2DM in the State of California and San Diego County respectively (Santibáñez, Yoon, Britton, \& Fernández, 2016). Furthermore, the highest percentage of patients diagnosed with T2DM belongs to the age group of 40-64, followed by age group 65-79. The alarming pervasiveness of the T2DM predicament prompted increased access and participation of various DSME programs (CDC, 2018). The emphasis on the promotion of self-care management at the primary care level is a crucial component in improving glycemic health outcomes.

\section{Evidence-based Interventions}

The literature review used several search engines to explore the best available evidence on DSMES. The primary databases used included CINAHL Plus, PubMed, Ovid, and Google Scholar. Terminologies employed for searching were as follows: T2DM self-care management, DSMES, diabetes self-care, diabetes self-care management, self-care behaviors, selfmanagement interventions, self-care interventions, and self-care activities. Articles that were used to support the proposed EBP project were guided by the evidence pyramid. Articles $<5$ years old were considered.

\section{Self-Care Management Education}

Yang and Fang (2016) specified that the primary armamentarium in glycemic control is health education. This EBP is focused on educating T2DM patients identified with $\geq 7 \%$ A1C in the importance of self-care management and support as an approach to promoting healthy glycemic control as recommended by the American Diabetes Association (ADA). A 30-minute tailored individualized education with emphasis on designated seven self-care behaviors of the 
Association of American Diabetes Educators (AADE) was used as a guide in attaining glycemic control within the normal limits after the EBP project interventions.

The DSME assists patients with T2DM in gaining knowledge, skills, and capabilities vital to self-management, while Diabetes Self-Management Support (DSMS) educates patients regarding coping skills and behaviors toward upholding learned diabetes self-care strategies (Powers et al., 2017). In the systematic review (SR) conducted by Bagnasco et al., (2014), the author cited that understanding the patient-specific educational needs are needed to provide appropriate strategies and interventions. These are essential in influencing better T2DM self-care management.

The types of instruction delivery, DSME engagement hours, and baseline A1C, are among the perceived factors that influence the success of a meaningful A1C outcome (Chrvala et al., 2016). Both DSME and DSMS should be designed according to patients' needs, culture, preference, and other factors influencing patient ability to better manage T2DM care. Various professional and nonprofessional healthcare members within the community settings can provide DSMS (Powers et al., 2016).

\section{Telephone-Based Support}

Currently, the use of various technologies in healthcare has improved the delivery of care. Utilization of telephone-based support intervention in patients with T2DM is one among others. This EBP project will be using telephone follow-up to call respondents after the provision of the initial 30-minutes of instruction as a strategy to support the perceived self-care management instructions. Sarayani et al. (2018) piloted a telephone-based intervention to patients taking oral medication for hyperglycemia. This resulted in increased adherence on medication and promoted self-care activities after three- and six-months follow-up. A reduced 
A1C was immediately noted at three months in the study. This was mentioned as attributed to patients' prior motivation to engage in a healthy lifestyle. This study concluded that telephonebased intervention delivered by trained nonprofessional health educators is a cost-effective option in T2DM care.

A mixed-method study embedded in a randomized controlled trial (RCT) piloted by Odnoletkova et al. (2016) concluded that even in the presence of already improved risk factors among T2DM patients, education delivery via telephone calls resulted in significantly reduced A1C level from baseline. The intervention was a provision of a monthly 30 -minute telephone session for five months with a certified diabetes nurse specialist. The diabetes education focuses on blood glucose self-monitoring, patient tailored lifestyle change, and prescribed medication therapy.

The constant reinforcement of DSMES through use of telephone-based intervention would benefit T2DM patients, specifically those who are in great need of support outside the routine patient-provider encounters in private practice settings. Beck et al., 2017, specified that it is imperative to patients with T2DM to receive DSME with ongoing support to improve glycemic outcome, thus reducing further disease complications.

\section{Diabetes Self-Management Questionnaire}

This EBP project will utilize the Diabetes Self-Management Questionnaire (DSMQ) to measure self-care management skills at baseline and during follow-up at three to eight months after the project intervention. Administration of a questionnaire is one of the several ways to explore T2DM patients' self-care behaviors towards their disease condition. Although numerous questionnaires are available to be used in studies, the DSMQ psychometric tool demonstrates a direct correlation between self-care activities and glycemic outcome measurements (Schmitt et 
al., 2013). This 16-item psychometric tool, which was introduced in 2013, was a reliable and valid instrument in assessing T2DM patient's self-care activities concerning their glycemic control (Bukhsh, Lee, Pusparajah, Schmitt, \& Khan, 2017). This first German instrument specifically inquires as to the individual's self-care activities pertaining to the last eight days (Schmitt et al., 2016).

The DSMQ included questions regarding an individual's nutrition, medication compliance, blood glucose self-monitoring, physical activities related to glycemic control, and healthcare provider encounters. A four-point Likert scale answers each question from 0 to 3 corresponding to "does not apply to me" and "applies to me very much" respectively. The higher the total calculated score indicates better self-care management. The review of DSMQ scores with patients would allow them to recognize that they have control over their disease and would empower them to be more vigilant in combatting T2DM.

\section{PICO Question}

P: T2DM patients, aged 18 and older, in a primary care setting with $\geq 7 \% \mathrm{~A} 1 \mathrm{C}$

I: Implementation of DSMES and administration of DSMQ

C: Current clinic practice

O: Reduce A1C level and increase self-care management behaviors

T: After follow-up at 3 to 8 months after program implementation

\section{Evidence-Based Practice Model}

The Rosswurm and Larrabee model uses strategies that promote adaptation to a new practice. It stimulates the clinician to use the six steps to EBP implementation integrated with quality initiative (QI) values, teamwork tools, and various other strategies (Melnyk \& FineoutOverholt, 2015). This model perfectly fits the proposed EBP project due to its simplicity, clarity, 
and concise instructions to make EBP change. The model identifies and prioritizes the most relevant issues requiring change, with emphasis on the ongoing monitoring and outcome indicators to guide the decision on whether to adopt or reject the new practice.

The initial step of the Rosswurm and Larrabee model stimulates the EBP project via assessment of a practice problem accomplished with the development of a PICOT (population, intervention, comparison, outcome, time) question (Melnyk \& Fineout-Overholt, 2015). The resources needed in piloting the EBP project was established within a clinical practice setting followed by project launching. The remaining five steps were used to guide the EBP project intended for practice use as a standard of care in a private practice setting. This model encourages dissemination of experiences gained from the initiated project, which was believed helpful for future attempts in establishing an EBP project in a clinical or organization setting (Melnyk \& Fineout-Overholt, 2015).

\section{Project Implementation/Process Plan}

Process indicators were used for data monitoring purposes in finding out if the EBP project will demonstrate a shift to healthy glycemic outcomes anticipating future practice change and adaptation. Patients who were at least 18 years of age and older, diagnosed with T2DM, and with $\geq 7 \%$ A1C level, were qualified to participate in this EBP project. The participation was voluntary.

The EBP project implementation began with the identification of T2DM patients with $\geq 7 \%$ A1C level results taken at baseline data collection in May 2018 and at follow-up after project intervention at 3 to 8 months. Tailored individualized 30-minute rigorous face-to-face DSMES educational intervention was provided to each respondent at baseline or could be given any time when assessed as appropriate. The instructions used the seven self-care behaviors of 
the AADE (2018) as a tool to guide T2DM education. The tool consists of education on healthful eating, physical activity, blood sugar monitoring, treatment plan compliance, ability to critically think, healthy coping skills, and risk reduction strategies that are known to predict T2DM outcomes.

A telephone-based intervention was also used to help reinforce and sustain selfmanagement educations that have been initiated. The intervention used a telephone-based mode of communication to fill the gap between appointment schedules in order to increase respondents follow up attendance and to motivate self-care activity engagement. The respondents were instructed to monitor and log compliance to the following self-care activities: blood glucose as instructed if applicable, nutrition, medication, physical activities, and various healthcare provider-related attendance consistent with the DSMQ tool. Both the respondents and the nurse practitioner (NP) will review available records pertaining to diabetes care at each telephonebased intervention follow-up to reinforce compliance to the initiated plan of care.

The administration of the DSMQ as baseline data for those identified to have A1C levels of $\geq 7 \%$ as the second process indicator was repeated after EBP intervention at 3 to 8 months follow-up. Each respondent was assisted by the NP to help assess daily self-care activities within the last eight weeks from the time of DSMQ administration.

\section{Evaluation Plan}

\section{Data Analysis}

The data for this EBP project were analyzed from baseline and at 3 to 8 months follow-up after project intervention. The collection of data started upon the respondent's agreement to participate in the EBP project implementation. Those who agreed were asked to complete the 
DSMQ form with the assistance of the NP. Various EBP project interventions were instituted thereafter.

Respondents were asked to have their A1C level drawn if the latest A1C results were not within the last three months of data gathering. The recruitment of the respondents commenced in May 2018 and was referred as the initial data collection. Ongoing data monitoring on DSMQ and A1C were established to document the impact of various evidence-based strategies used in the EBP project implementation — as stated in the above intervals. Available data assisted in analyzing the trend of the respondent's participation and identified barriers in the implemented EBP project with the established necessary adjustments.

\section{Sustainability}

Sustainability of this EBP project significantly increased the possibilities of achieving healthy glycemic control among T2DM patients seen in this clinic practice. For this project, there were several proposed strategies to maintain improved healthy glycemic outcome. These include: 1) training all stakeholders to assist and review DSMQ forms as part of diabetes care; 2) creating a T2DM binder for standardized protocols; 3) reviewing contents of education materials with stakeholders; 4) providing a script intended for telephone calls; and 5) meeting every three months or anytime if needed to help sustain the EBP project. This EBP project would like to establish a positive outcome on both the patients and the stakeholders to gain support in the sustenance of this effort and future EBP projects to be conducted in this practice.

\section{Evaluation of Intervention and Outcomes}

The EBP project outcome indicators required data monitoring that promoted respondents' healthy glycemic control. The first outcome indicator was to improve DSMQ scores, with increased DSMQ scores as desirable outcome. This psychometric tool possesses a strong 
relationship between self-care activities and glycemic outcome (Schmitt et al., 2013). The expected result of increasing DSMQ scores from baseline was achieved after project intervention. The DSMQ scores rose from 11.1 to 19.8 after implementation of this EBP project.

The purpose of this EBP project is to continually intensify respondents' DSMQ scores and those of patients diagnosed with T2DM at this practice. The EBP project used the DSMQ as part of the usual care in this practice setting, administered every three months and beyond, or otherwise per the needs of T2DM patients. It ensures the sustainability of diabetes self-care behaviors learned by the respondents and those others who are at high risk for developing T2DM and T2DM diagnosed patients seen in this clinic.

The recommended A1C goals are as follows: $<7 \%$ for non-pregnant adults, $<6.5 \%$ for patients who do not exhibit hypoglycemia, and $<8 \%$ intended for those who experience hypoglycemic episodes (ADA, 2018). The goal for this EBP project is to increase the number of respondents with $\mathrm{A} 1 \mathrm{C}$ levels that are within or close to the ADA recommended level- also referred to as the second indicator. After project intervention, patients A1C level average decreased from $8.8 \%$ to $7.5 \%$ at follow-up among identified patients with $\mathrm{A} 1 \mathrm{C} \geq 7 \%$. The results will continue to be monitored every three months until the individualized goal is reached to $100 \%$ after the first year and beyond. The various strategies perceived to increase adherence to self-care will be used to improve DSMQ scores and achieve healthy glycemic control among T2DM respondents.

\section{Cost Benefit Analysis}

The average total annual cost of each patient with controlled diabetes who receives treatment is $\$ 17,500$ while the average yearly cost for each patient with uncontrolled diabetes is $\$ 22,410$ (Dall et al., 2016). This EBP project has a total of eight respondents. If an average NP 
hourly rate is $\$ 60$, and will be compensated to work for a total of an extra 30 minutes for every eight respondents for this EBP project, the cost would be \$240. If this EBP project will help patients promote healthy glycemic levels, the difference between $\$ 17,500$ health expenditures for patients with controlled T2DM and the annual EBP project healthcare cost (\$240) which is $\$ 17,260$, these will be considered as other related costs of diabetes care. Given the average annual healthcare cost for each patient with uncontrolled T2DM is $\$ 22,410$, less $\$ 17,500$ as the annual healthcare cost for each patient with controlled diabetes is $\$ 4,910$ as the average costbenefit analysis. Therefore, the total yearly cost benefits of $\$ 39,040$ for T2DM patients with healthy glycemic control is within the ADA recommended level. The return on investment (ROI) will be $\$ 4,910$ divided by 17,500 is equal to 0.28 or $28 \%$ annually for each patient with controlled T2DM.

Healthcare Effectiveness Data and Information (HEDIS) is another incentive program that provides rewards to providers delivering highest quality preventive services (Meridian, 2018). These healthcare providers may receive extra revenue from $\$ 20$ to $\$ 100$ per patient annually when glycemic control is met as recommended for patients with T2DM. The pay-forperformance incentive program would provide the clinic with a maximum extra yearly revenue of $\$ 800$ for eight patients.

\section{Project Development and Implementation Timelines}

The requirements for the EBP project were identified on February 20, 2018, including the the clinic site mentor, the location where the study will be conducted, and the letter of support (LOS). The University of San Diego (USD) Institutional Review Board (IRB) initial project proposal submission took place on April $9^{\text {th }}, 2018$ and was approved on April $13^{\text {th }}, 2018$. The project was implemented on May $1^{\text {st }}, 2018$ in National City, California. The project inclusion 
criteria were: patients with T2DM diagnosis who had A1C of $\geq 7 \%$ and were at least aged 18 years. A total of 442 patients from January 2018 to February 2019 were included in this EBP project.

During baseline data collection, T2DM patients with $\geq 7 \%$ A1C within the last two months including May 2018 were identified and were asked to participate in the EBP project. A total of eight T2DM respondents agreed to participate. The DSMQ scores were obtained after the administration of the DSMQ, then followed by the 30-minute face-to-face tailored individualized DSMES, inspired with the AADE's seven self-care behaviors provided by the NP during a regular clinic visit. The A1C levels and the DSMQ scores were obtained at baseline and three to eight months after the EBP interventions. The outcomes of the EBP project were evaluated and finalized on February 28, 2019.

\section{Project Results and Anticipated Future Outcomes}

The DSMES EBP project has short (3-12 months) and long-term (13-24 months) outcomes. A total of $21.4 \%$ of T2DM patients seen in the private practice were identified to have $\geq 7 \%$ A1C. About $11.4 \%$ of respondents participated in this EBP project. The short-term outcomes from baseline after three to nine months interventions resulted to the following measurements: 1) increased average DSMQ scores from 11.1 to 19.8 and 2) reduced average A1C level from $8.8 \%$ to $7.5 \%$ after EBP interventions.

The long-term outcome will be to improve the glycemic control and increase selfmanagement skills of the remaining $10 \% \mathrm{~T} 2 \mathrm{DM}$ patients with $\geq 7 \% \mathrm{~A} 1 \mathrm{C}$ at baseline measurements through the various DSMES interventions used in this EBP project. Increased patient participation in self-care activities will lead to likely positive health outcomes, which eventually would yield to increased revenue in the private practice clinic. 
Figure 1.

Pre- and Post-Average AlC level

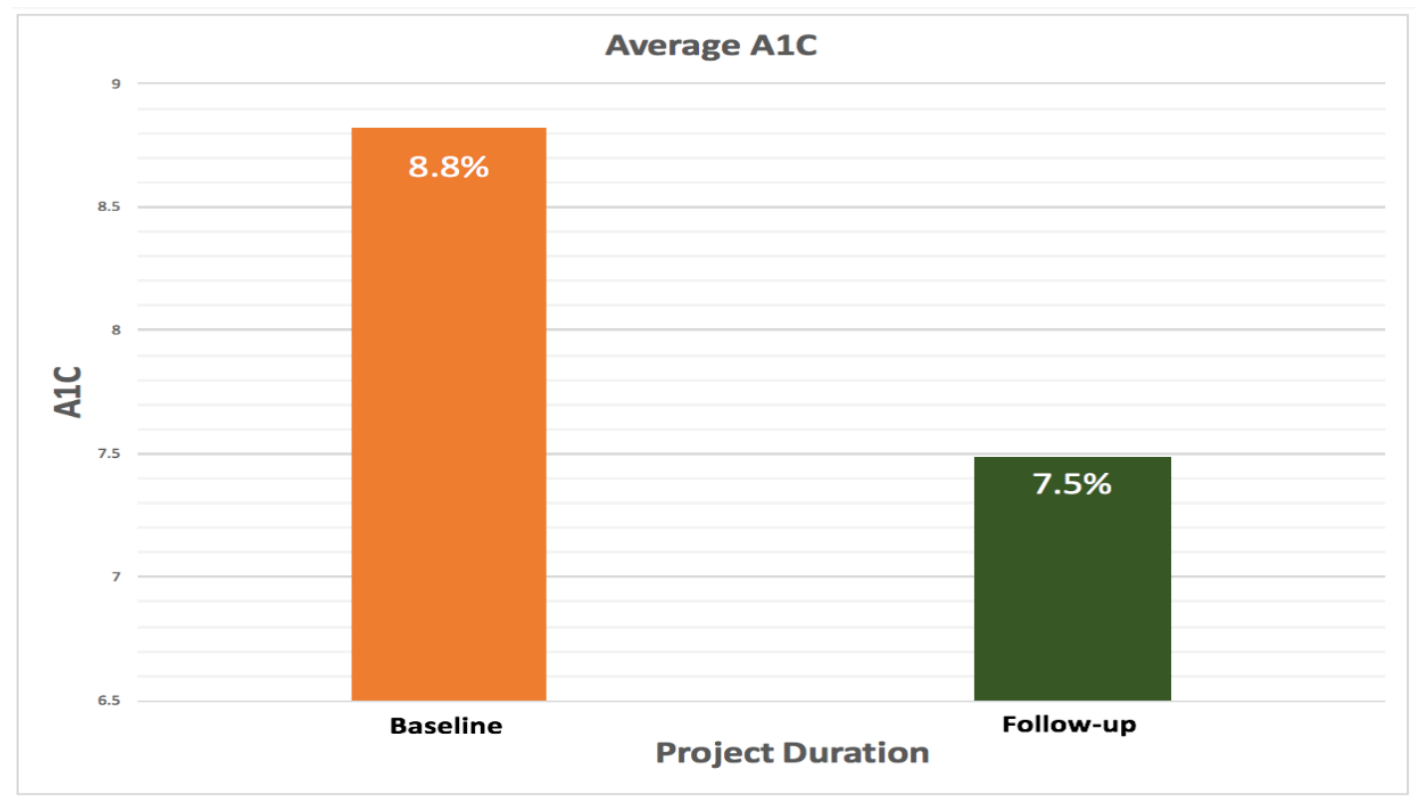

Figure 1. Average A1C levels from baseline and follow-up after EBP intervention

Figure 2.

Pre- and Post-Average AlC level

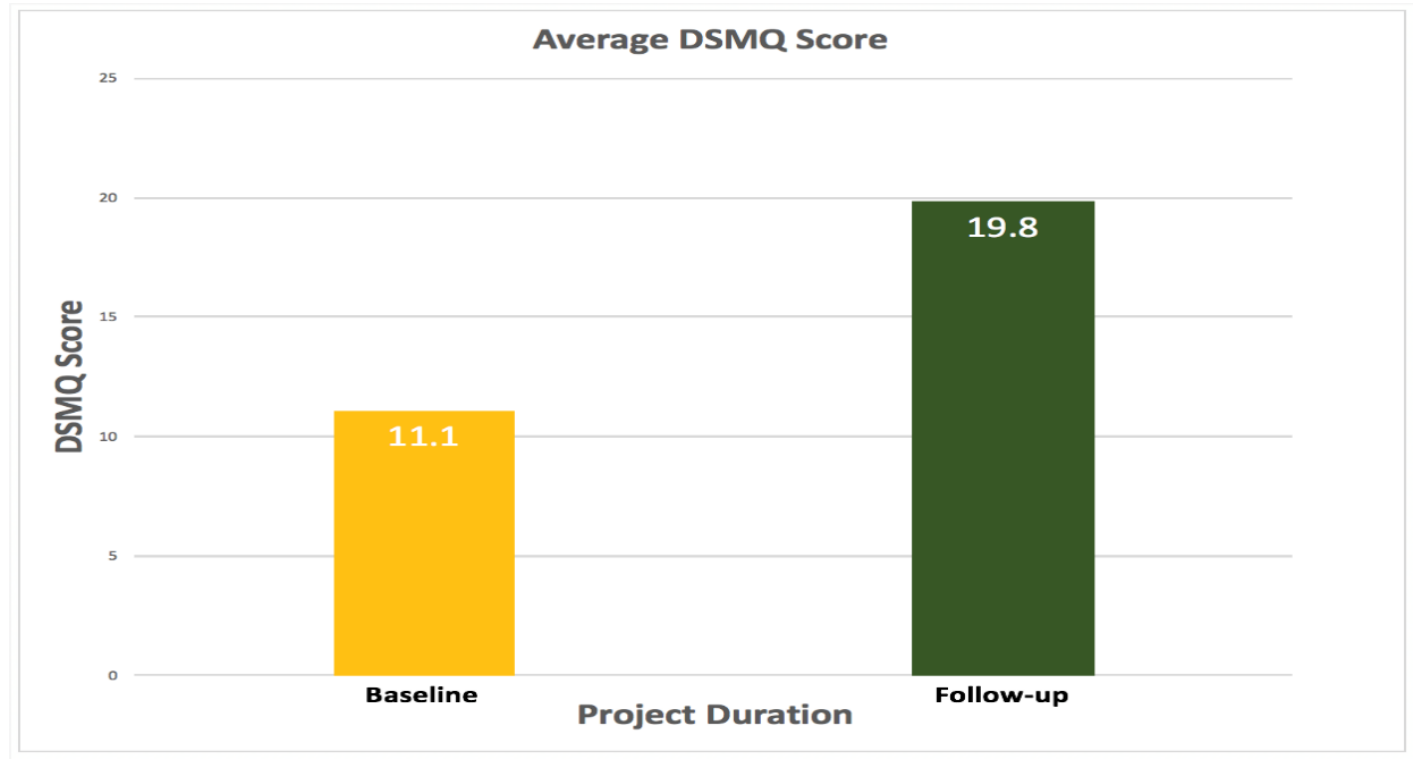

Figure 2. Average DSMQ score from baseline and follow-up after EBP intervention 


\section{Discussion}

In this EBP project, the utilization of DSMES intervention in the clinic during routine patient visits resulted in the improvement of glycemic index among the eight T2DM respondents identified with $\geq 7 \%$ A1C level. Alongside, was the increase in DSMQ scores as an indicator of improved self-care activities related to T2DM. Using the AADE's seven self-care behaviors to guide the DSME was found to be useful when combined with telephone follow-up support of the learned instructions. Most respondents in this EBP project belong to the older adult population. Combining the various tailored interventions among older adults is effective in reducing A1C levels (Sherifali et al., 2015).

Respondents cognizance that they have the power to take control of their glycemic outcomes was compelling. This was done through their active participation in self-care disease management and partnering with their healthcare providers. Understanding the $\mathrm{A} 1 \mathrm{C}$ level, vis-àvis the likelihood of acquiring various overwhelming complications brought by uncontrolled T2DM, made the respondents mindful of self-care activities that may enhance their glycemic outcomes.

The results of this EBP project were consistent with most studies conducted using DSMES. This specifically improved A1C levels. This EBP project assisted the respondents in being more vigilant regarding healthy food choice options, compliance with treatment, and increasing self-care activities that will help improve their glycemic index within the recommended levels.

\section{Limitations}

This EBP project has limitations. One is the limited number of respondents — only eight were recruited. Some potential respondents who were identified as qualified for the project were 
not included due to changes in their health insurances - most were not contracted with the clinic. Some patients changed their health insurance to companies contracted with the clinic, but some kept their insurance group and looked for new health providers to establish care instead.

Another limitation involved follow-up. Initially, the patient's follow-up was scheduled three months after the interventions were provided. The change of health insurance resulted in the delay of patients' follow-up ranging from three months to eight months after DSMES interventions. Despite the limitations, the EBP project demonstrated reduced average A1C levels and increased average DSMQ scores.

\section{Conclusions}

Type 2 diabetes mellitus has been an ongoing health issue causing huge expenditures for many decades, yet it is preventable. This EBP project emphasizes the position of DSMES and the DSMQ within the primary care setting. Patients can be taught. When given suitable education and support tailored to their specific needs and preferences, through multifaceted diabetes education and support these patients could be empowered to take control of their health. Achieving healthy glycemic control within the recommended level would prevent progression to various potential disease complications leading to increased healthcare cost. The implementation of this EBP project fostered reduced A1C levels among the eight diagnosed T2DM respondents with $\geq 7 \% \mathrm{~A} 1 \mathrm{C}$ levels as seen in this private practice clinic. This, alongside an increased recognition of the importance of self-care T2DM management. Adaptation and sustenance of this EBP project within the practice would assist in increasing clinic revenue, thus contributing to alleviating the ever-growing healthcare dollar spending related to T2DM and its associated complications. 


\section{Implications for Clinical Practice}

To achieve healthy glycemic control, primary care providers must tailor individualized DSMES topics and teaching methods according to patient's needs and preferences when using various evidence-based (EB) strategies. Teaching and reinforcing the AADE 7 designated selfcare behaviors was effective in improving glycemic control of T2DM patients with $\geq 7 \%$ A1C. Administration of DSMQ assists healthcare providers in identifying patient self-care behaviors needing improvement toward promoting A1C at recommended levels. This EB project outcome, if well circulated within the community, may potentially influence adaptation to local primary care clinics toward encouraging and sustaining patient glycemic control. Increased emphasis on recognition of self-care management, specifically in the primary care setting, would promote healthy glycemic control and reduce healthcare cost - at least within the County of San Diego. 


\section{References}

American Association of Diabetes Educators (2019). AADE7 self-care behaviors. Retrieved March 11, 2019 from https://www.diabeteseducator.org/patients/aade7-self-carebehaviors

American Diabetes Association (2017). Standards of Medical Care in Diabetes - 2017:

Diagnostic test for diabetes. Diabetes Care, 40(Suppl. 1): S44-S47. doi:10.2337/dc17-

S008. Retrieved March 08, 2018 from Retrieved November 18, 2017 from http://care.diabetesjournals.org/content/diacare/suppl/2016/12/15/40.Supplement_1.DC1/ DC_40_S1_final.pdf

American Diabetes Association (2017). Standards of Medical Care in Diabetes - 2017:

Prevention or delay of type 2 diabetes. Diabetes Care, 40(Suppl. 1): S44-S47. doi: 10.2337/dc17-S008. Retrieved March 08, 2018 from http://care.diabetesjournals.org/content/diacare/suppl/2016/12/15/40.Supplement_1.DC1/ DC_40_S1_final.pdf

American Diabetes Association (2018). Economic Costs of Diabetes in the U.S. in 2017. Diabetes Care, dci180007. doi.10.2337/dci18-0007. Retrieved March 25, 2018 from http://care.diabetesjournals.org/content/early/2018/03/20/dci18-0007

American Diabetes Association (2018). Glycemic targets: Standards of medical care in diabetes-2018. Diabetes Care, 41(Supplement 1): S55-S64. doi.10.2337/dc18-S006 American Diabetes Association (2018). The Burden of Diabetes in California. Retrieved March 25, 2018 from http://main.diabetes.org/dorg/assets/pdfs/advocacy/state-factsheets/California2018.pdf 
Bagnasco, A., Di Giacomo, P., Da Rin Della Mora, R., Catania, G., Turci, C., Rocco, G., \& Sasso, L. (2014). Factors influencing self-management in patients with type 2 diabetes: A quantitative systematic review protocol. Journal of Advanced Nursing, 70(1), 187-200. doi:10.1111/jan.12178

Beck, J., Greenwood, D. A., Blanton, L., Bollinger, S. T., Butcher, M. K., Condon, J. E., \& ... Rhinehart, A. S. (2017). 2017 National standards for diabetes self-management education and support. Diabetes Care, 40(10), 1409-1419. doi:10.2337/dci17-0025

Bukhsh, A., Lee, S., Pusparajah, P., Schmitt, A., \& Khan, T. M. (2017). Psychometric properties of the Diabetes Self-Management Questionnaire (DSMQ) in Urdu. Health and quality of life outcomes, 15(1), 200. doi:10.1186/s12955-017-0776-8

Bullard, K. M., Ali, M. K., Imperatore, G., Geiss, L. S., Saydah, S. H., Albu, J. B., ... Gregg, E. W. (2015). Receipt of glucose testing and performance of two US diabetes screening guidelines, 2007-2012. Plos One, 10(4), e0125249. doi:10.1371/journal.pone.0125249

Centers for Disease Control and Prevention (2017). County data. Retrieved March 01, 2018 from https://www.cdc.gov/diabetes/atlas/countydata/atlas.html

Center for Disease Control and Prevention (2018). Diabetes Self-Management Education and Support. Retrieved from https://www.cdc.gov/diabetes/programs/stateandlocal/resources/self-managementeducation-support.html

Centers for Disease Control and Prevention (2017). New CDC report: More than 100 million Americans have diabetes or prediabetes. Retrieved March 16, 2018 from https://www.cdc.gov/media/releases/2017/p0718-diabetes-report.html 
Centers for Disease Control and Prevention (2017). Type 2 diabetes. Retrieved February 16, 2018 from https://www.cdc.gov/diabetes/basics/type2.html

Chrvala, C. A., Sherr, D., \& Lipman, R. D. (2016). Diabetes self-management education for adults with type 2 diabetes mellitus: A systematic review of the effect on glycemic control. Patient Education \& Counseling, 99(6), 926-943. doi:10.1016/j.pec.2015.11.003

Dall, T. M., Yang, W., Halder, P., Franz, J., Byrne, E., Semilla, A. P., ... Stuart, B. (2016). Type 2 diabetes detection and management among insured adults. Population Health Metrics, 14, 43. doi.10.1186/s12963-016-0110-4

García-Pérez, L.-E., Álvarez, M., Dilla, T., Gil-Guillén, V., \& Orozco-Beltrán, D. (2013). Adherence to therapies in patients with type 2 diabetes. Diabetes Therapy, 4(2), 175194. doi.org/10.1007/s13300-013-0034-y

Kalyani, R. R., Golden, S. H., \& Cefalu, W. T. (2017). Diabetes and Aging: Unique Considerations and Goals of Care. Diabetes Care, 40(4), 440-443. doi.org/10.2337/dci17-0005. Retrieved from http://care.diabetesjournals.org/content/40/4/440

Melnyk, B.M. \& Fineout-Overholt, E. (2015). Evidence-based practice in nursing and healthcare: a guide to best practice (3rd ed.). Philadelphia, PA: Wolters Kluwer \& Lippincott, Williams \& Wilkins.

Meridian (2018). Meridian incentive program: Meridian incentive program overview. Retrieved from https://corp.mhplan.com/ContentDocuments/default.aspx?x=qnaUA0T9FoxRn6OpIc699 Tdx9YYr/CfjwKx25eaVxVc00nVxuitXAzoJx18ihDBBwtSNoK9xWsWw9u8HTctYXQ $==$ 
Odnoletkova, I., Buysse, H., Nobels, F., Goderis, G., Aertgeerts, B., Annemans, L., \& Ramaekers, D. (2016). Patient and provider acceptance of telecoaching in type 2 diabetes: A mixed-method study embedded in a randomized clinical trial. BMC Medical Informatics \& Decision Making, 161-8. doi:10.1186/s12911-016-0383-3

Powers, M. A., Bardsley, J., Cypress, M., Duker, P., Funnell, M. M., Fischl, A. H., \& ...Vivian, E. (2017). Diabetes self-management education and support in type 2 diabetes. A joint position statement of the American Diabetes Association, the American Association of Diabetes Educators, and the Academy of Nutrition and Dietetics. The Diabetes Educator, 43(1), 40-53. doi:10.1177/0145721716689694

Rowley, W. R., Bezold, C., Arikan, Y., Byrne, E., \& Krohe, S. (2017). Diabetes 2030:

Insights from yesterday, today, and future trends. Population Health Management, 20(1), 6-12. doi:10.1089/pop.2015.0181

Santibáñez, M., Yoon, S., Britton, J., \& Fernández, A. (2016). Border health status report to the legislature 2016. California Department of Public Health: Office of Binational Border Health. Retrieved from https://www.cdph.ca.gov/Programs/CID/OBBH/CDPH\%20Document\%20Library/2016 \%20BHSR\%20FINAL\%20docx.pdf

Sarayani, A., Mashayekhi, M., Nosrati, M., Jahangard-Rafsanjani, Z., Javadi, M., Saadat, N.,... Gholami, M. (2018). Efficacy of a telephone-based intervention among patients with type-2 diabetes; a randomized controlled trial in pharmacy practice. International Journal of Clinic Pharmacy. doi:10.1007/s11096-018-0593-0

Schmitt, A., Gahr, A., Hermanns, N., Kulzer, B., Huber, J., \& Haak, T. (2013). The diabetes self-management questionnaire (DSMQ): Development and evaluation of an instrument 
to assess diabetes self-care activities associated with glycaemic control. Health and Quality of Life Outcomes, 11, 138. doi.org/10.1186/1477-7525-11-138

Schmitt, A., Reimer, A., Hermanns, N., Huber, J., Ehrmann, D., Schall, S., \& Kulzer, B. (2016). Assessing diabetes self-management with the diabetes self-management questionnaire (DSMQ) can help analyse behavioural problems related to reduced glycaemic control. PLOS ONE, 11(3), e0150774. doi.org/10.1371/journal.pone.0150774

Sherifali, D., Bai, J. -W., Kenny, M., Warren, R., \& Ali, M. U. (2015). Diabetes selfmanagement programmes in older adults: a systematic review and meta-analysis. Diabetic Medicine, 32(11), 1404-1414. doi:10.1111/dme.12780

Shrivastava, S. R., Shrivastava, P. S., \& Ramasamy, J. (2013). Role of self-care in management of diabetes mellitus. Journal of Diabetes \& Metabolic Disorders, 12:14. doi.10.1186/2251-6581-12-14

Yang, Q., \& Fang, P. (2016). Impact of the conversation map tools in patients with type 2 diabetes mellitus. Medicine, 95(40). doi.10.1097/MD.0000000000004664 